\title{
Gastrointestinal Anastomotic Leak, CTCAE
}

National Cancer Institute

\section{Source}

National Cancer Institute. Gastrointestinal Anastomotic Leak, CT CAE. NCI Thesaurus.

Code C143507.

A finding of leakage due to breakdown of a gastrointestinal anastomosis (surgical connection of two separate anatomic structures). 